\title{
Estimating the sampling efficiencies of a framed midwater trawl and ring net for zooplankton using an acoustic method
}

Zhen Lu

Fisheries Resources Institute, Japan Fisheries Research and Education Agency,Japan, roshin@affrc.go.jp

Tohru Mukai

Faculty of Fisheries Sciences, Hokkaido University, Japan

Yasuzumi Fujimori

Faculty of Fisheries Sciences, Hokkaido University, 3-1-1, Minato-cho, Hakodate, Hokkaido, Japan

Kohji lida

Faculty of Fisheries Sciences, Hokkaido University, 3-1-1, Minato-cho, Hakodate, Hokkaido, Japan

Follow this and additional works at: https://jmstt.ntou.edu.tw/journal

Part of the Fresh Water Studies Commons, Marine Biology Commons, Ocean Engineering Commons, Oceanography Commons, and the Other Oceanography and Atmospheric Sciences and Meteorology Commons

\section{Recommended Citation}

Lu, Zhen; Mukai, Tohru; Fujimori, Yasuzumi; and lida, Kohji (2021) "Estimating the sampling efficiencies of a framed midwater trawl and ring net for zooplankton using an acoustic method," Journal of Marine Science and Technology. Vol. 29: Iss. 2, Article 3.

DOI: $10.51400 / 2709-6998.1080$

Available at: https://jmstt.ntou.edu.tw/journal/vol29/iss2/3

This Research Article is brought to you for free and open access by Journal of Marine Science and Technology. It has been accepted for inclusion in Journal of Marine Science and Technology by an authorized editor of Journal of Marine Science and Technology. 


\title{
Estimating the Zooplankton Sampling Efficiencies of a Framed Midwater Trawl and a Ring Net Using an Acoustic Method
}

\author{
Zhen Lu $^{\mathrm{a}, \mathrm{c}, *}$, Tohru Mukai ${ }^{\mathrm{b}}$, Yasuzumi Fujimori ${ }^{\mathrm{b}}$, Kohji Iida ${ }^{\mathrm{b}}$ \\ a Graduate School of Fisheries Sciences, Hokkaido University, 3-1-1, Minato-cho, Hakodate, Hokkaido 041-8611, Japan \\ ${ }^{\mathrm{b}}$ Faculty of Fisheries Sciences, Hokkaido University, 3-1-1, Minato-cho, Hakodate, Hokkaido 041-8611, Japan \\ ${ }^{\mathrm{c}}$ Fisheries Resources Institute, Japan Fisheries Research and Education Agency, 3-27-5, Shinhama-cho, Shiogama, Miyagi 985-0001, \\ Japan
}

\begin{abstract}
It is well known that there is bias using different sampling gear, such as a framed midwater trawl (FMT) and a ring net, when measuring the density and length distribution of target species. This limit is characterized by the sampling efficiency of the gear. Acoustic monitoring can be used to determine the sampling efficiencies of this gear, as its noninvasive, wide-range sweeps provide more reliable estimates of absolute abundance of the target species. The density measured by the gear can then be standardized by multiplying the initial density measurement by the derived sampling efficiency. In this study, we compared the estimated densities of the dominant zooplankton in the sound scattering layer (SSL) from acoustic monitoring to the densities of the same species measured using the FMT and ring net. The respective sampling efficiencies of this gear for zooplankton categories was then determined using linear regression models. For small Euphausiidae and Copepoda, the sampling efficiency of ring net was higher than that of FMT. In contrast, the ring net was less effective than FMT for large Euphausiidae. These results highlight that the entering and retention rates of the species depend on the type and characteristics of the survey gear, as well as the size and swimming ability of the target species.
\end{abstract}

Keywords: Sampling efficiency, Acoustic method, FMT, Ring net, Zooplankton

\section{Introduction}

$\mathrm{Z}$ ooplankton, which are important prey for large fish and whales, occupy the lower location of the food chain in marine ecosystems [15]. Accurate estimates of their distribution and biomass could be helpful in the effective management of fishery resources. Copepods are generally small, $10 \mathrm{~mm}$ or less in length, and they swim fine for short distance but cannot fight current. Small plankton nets with a small mouth area and small mesh openings, such as the NORPAC net, bongo net, and ring net, are hauled vertically or obliquely at relatively low speeds of about $1 \mathrm{~m} \mathrm{~s}^{-1}$. However, since the mesh opening is small, the filtration rate is also small and an overflow phenomenon occurs, which limits the volume of water entering the net and passing through the mesh [24]. In addition, the small area of the net mouth and the low towing speed increase avoidance of the net by more motile zooplankton [27]. Consequently, the nets are highly size- and species-selective, a fact that reduces sampling efficiency by limiting the number of species caught in the nets.

* Corresponding author. Fisheries Resources Institute, Japan Fisheries Research and Education Agency, 3-27-5, Shinhama-cho, 
On the other hand, large zooplankton, such as krill (euphausiids), has body lengths of several centimeters and a much greater swimming ability than copepods, so that it is difficult to collect them with small plankton nets. Instead, large zooplankton are caught using sampling gear such as the FMT that have a fixed mouth frame, a large mesh opening, and are towed at relatively fast speeds (3 4 knots). However, the large mesh openings cause small organisms to escape from the trawl [5], which results in selectivity and reduces the sampling efficiency for smaller species.

These gear limitations make it difficult to completely characterize the composition, length distribution, size and absolute abundance of the target species. It is necessary to use sampling gear that is suitable for the target organism and to determine the length selectivity and sampling efficiency of the gear if the aim is to quantitatively evaluate species aggregations. Moreover, when using different or newly developed sampling gear, it is also necessary to compare the sampling efficiency of new and old gear in order to make the results from different surveys and cruises more comparable [2,25].

It is known that the sound scattering layer (SSL) in oceans around the world mainly comprises zooplankton and micronekton [10], which are important targets for better understanding their biomass across different areas and as markers of the potential presence of commercially important fish species. Echo-sounders have mainly been used for biological surveys of the SSL $[9,14,16,19]$, using a non-invasive sampling technique to conduct quick and efficient surveys over wide areas. Lu et al. [17] developed a method of using acoustic information to estimate the sampling efficiency of FMT trawling for juvenile fish. In this paper, we focus on improving the quantitative sampling of zooplankton using both FMT and ring nets. We aimed to determine the sampling efficiency of both types of gear for different taxa and body lengths of zooplankters by comparing the densities of zooplankton caught in each net to reference densities derived from quantitative echo-sounder observations.

\section{2. . Material and methods}

\subsection{Data sampling}

Experiments were carried out at Station "K" outside the mouth of Funka Bay, Hokkaido (Fig. 1), in April, May, and June 2011 aboard T/S Ushiomaru

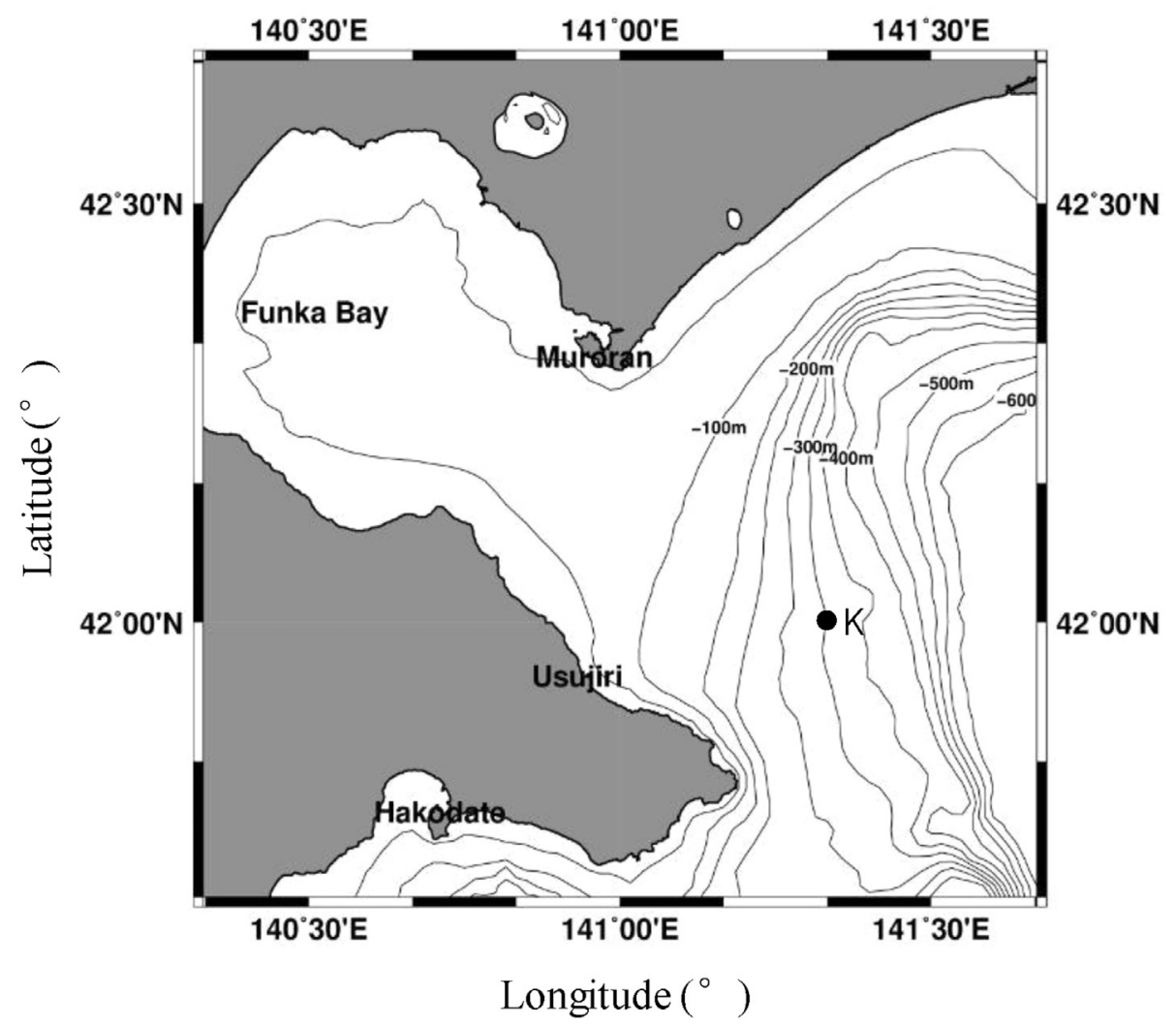

Fig. 1. Survey area with Station " $K$ " $\left(42^{\circ} 00^{\prime} \mathrm{N}, 141^{\circ} 20^{\prime} \mathrm{N}\right)$ situated in a total water depth of $300 \mathrm{~m}$ outside the mouth of Funka Bay, Hokkaido, Japan. 
$(179 \mathrm{t})$. The net samples were collected in a total water depth of $300 \mathrm{~m}$ using a framed midwater trawl (FMT, net mouth area $4 \mathrm{~m}^{2}$, mesh opening $1.5 \mathrm{~mm}$ ) [11] that was horizontally towed at a speed of approximately 3 knots (about $1.5 \mathrm{~m} \mathrm{~s}^{-1}$ ) through the middle of the SSL (as seen by the quantitative echosounder, Fig. 2). A ring net with a net mouth diameter of $80 \mathrm{~cm}$ (mouth area $0.5 \mathrm{~m}^{2}$, mesh opening 0.5 $\mathrm{mm}$ ) was also used to collect zooplankton by hauling the net vertically at about $1 \mathrm{~m} \mathrm{~s}^{-1}$. A depth logger (MDS5, Alec) was attached to the mouth of both kinds of sampling gear to confirm the towing depth. A flowmeter (RIGO) was attached to the upper part of FMT and to the net mouth of the ring net to calculate the filtered water volume of each haul.

The collected organisms were preserved on deck using $10 \%$ formalin solution and later divided into 1/2-1/256 aliquots by using a Motoda plankton divider [22]. Zooplankton was classified into five categories: Euphausiidae, Copepoda, Amphipoda, Chaetognatha and others. The number of individuals collected was counted for each category and then divided by the filtered water volume to calculate the net density. Total lengths (TL), rounded to the nearest $0.1 \mathrm{~mm}$, were measured for euphausiids, amphipods, and chaetognaths, and the prosome length (PL) was measured for copepods by using electronic calipers (Mitutoyo, Absolute 500). Hereafter, body length (BL) is used to refer to the lengths of all zooplankton. Wet weights, rounded to the nearest $0.01 \mathrm{mg}$, were measured using electronic scales (METTLER, AE200).

The acoustic data were recorded using a quantitative echo-sounder EK-60 (Simrad) with a frequency of $120 \mathrm{kHz}$, pulse width of $1.024 \mathrm{~ms}$, and pulse interval of $1 \mathrm{~s}$. The EK-60 was calibrated using a tungsten-carbide sphere with a diameter of 38.1 mm (WC 38.1) following the method described by Foote et al. [4]. Echograms were processed using the hydroacoustic data-processing software Echoview 4.0 (Echoview software), and the mean $S V$ (volume backscattering strength) was calculated at the ring net haul sites and along the FMT tow trajectories. For the FMTs, $S V$ was calculated for a width of $4 \mathrm{~m}$ (frame height is $2 \mathrm{~m}$ ) and at the towing depth (based on the depth sensor attached to the FMT) for the duration of each tow (Fig. 2). For the ring net, mean $S V$ was calculated along the trajectory of the net superimposed on the echogram (Fig. 2), which was derived using the depth logger data and the duration of the net haul.

\subsection{Estimation of sampling efficiency using acoustic data}

Sampling efficiency, $q$, can be expressed as the ratio of trawl catch per haul, $C$, and the actual number of fish, $N$, in the water column that the net mouth passed through [12]:

$q=C / N$

$C$ is expressed as the product of net density $\rho_{T r}$ and the filtered water volume $V_{T r}$ :

$C=\rho_{T r} V_{T r}$

The actual number of fish can be estimated from acoustic information using the following from Ref. [9]:

$$
\begin{aligned}
& N=\rho_{A c} V_{A c} \\
& \rho_{A c}=S_{v} / \sigma_{b s}
\end{aligned}
$$

where $\rho_{A c}\left(\right.$ ind. $\left.\mathrm{m}^{-3}\right)$ is acoustic density, $V_{A c}\left(\mathrm{~m}^{3}\right)$ is the swept water volume by net mouth area, $S_{v}\left(\mathrm{~m}^{-3}\right)$

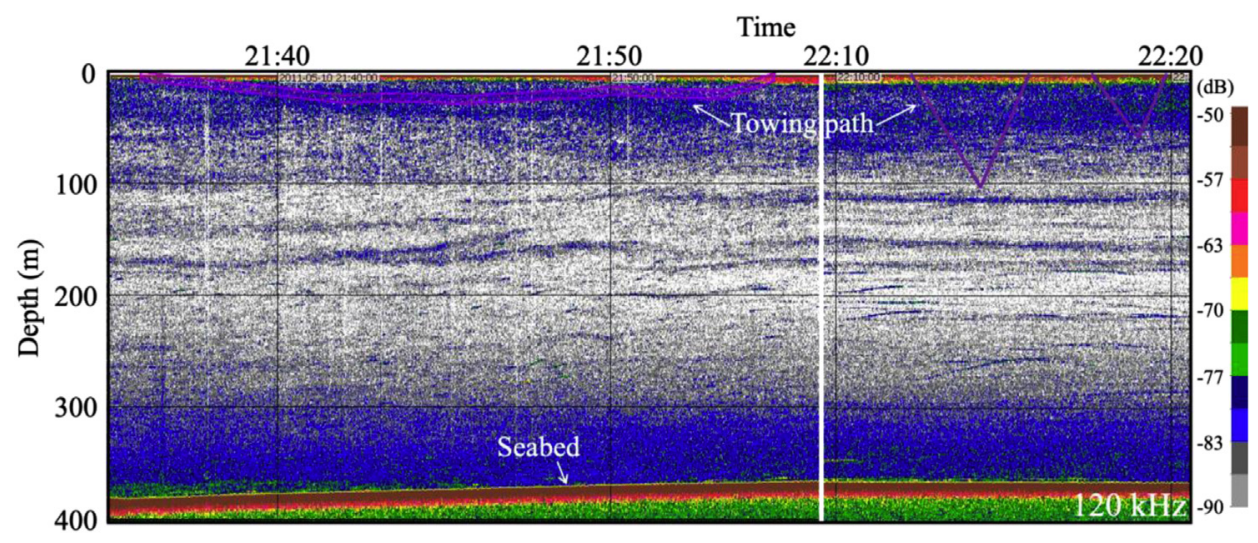

Fig. 2. A typical echogram with towing path on May 10, 2011. The left side of the figure (split by the thick white line) shows an echogram during the FMT towing No.10 and the right side is during the ring net hauls No.7 and No.8. Towing path (purple) was drew on echogram to calculate average $S V$. 
is the volume backscattering coefficient (equivalent to $S V$ in decibels), and $\sigma_{b s}$ is the backscattering cross section (equivalent to Target Strength (TS) in decibels).

$V_{T r}$ and $V_{A c}$ are expressed by:

$V_{T r}=A x / R c$

$V_{A c}=v t A$

$V_{T r}=f V_{A c}$

where, $A\left(\mathrm{~m}^{2}\right)$ is the net mouth area of the sampling gear, $x$ is the rotation number of the flowmeter, $R c$ $\left(\mathrm{m}^{-1}\right)$ is the rotation number per $1 \mathrm{~m}$ towing obtained from calibration of the flowmeter, $v\left(\mathrm{~m} \mathrm{~s}^{-1}\right)$ is the towing speed, $t(s)$ is the towing time, and $f$ is the filtration rate.

The filtration rate is calculated using the ratio between the volume calculated from the flowmeter and the volume of the water column that the net passed through, which is expressed as the product of the towing speed, towing time, and opening area [1]. The filtration rates applied in this study were 0.8 for the FMT, which was the mean value in June 2013, and 0.9 for the $80 \mathrm{~cm}$ ring net, which was the mean value in April 2011.

The volume backscattering coefficient can be derived using:

$q=\frac{f \rho_{T r} \sigma_{b s}}{S_{v}}$
When the target organism is a single taxon and $S_{v}$ is measured by a quantitative echo-sounder, $\sigma_{b s}$ and $\rho_{T r}$ can be calculated using length and density from the sampling gear, and the sampling efficiency $q$ can be estimated for mean size (Fig. 3).

Since various types of zooplankton are mixed in the sea, and $\sigma_{b s}$ also differs for different body lengths and species, measured $S_{v}$ was expressed as the sum of the products of $\rho_{T r}$ and $\sigma_{b s}$ for the target zooplankton when $q=1$ :

$S_{v}=\rho_{T r 1} \sigma_{b s 1}+\rho_{T r 2} \sigma_{b s 2}+\cdots+\rho_{T r m} \sigma_{b s m}+\epsilon$

where, $m$ is the zooplankton category and $\epsilon$ is residual sum of squares.

When the hauls are performed $n$ times, $n$ equation will be obtained accordingly. However, the sampling efficiency for each organism was assumed to be constant regardless of the number of hauls. Therefore, $S_{v}$ of each haul could be expressed by:

$$
\begin{aligned}
& S_{v}^{1}=\frac{f^{1} \rho_{T r 1}^{1} \sigma_{b s 1}^{1}}{q_{1}}+\frac{f^{1} \rho_{T r 2}^{1} \sigma_{b s 2}^{1}}{q_{2}}+\cdots+\frac{f^{1} \rho_{T r m}^{1} \sigma_{b s m}^{1}}{q_{m}}+\epsilon \\
& S_{v}^{2}=\frac{f^{2} \rho_{T r 1}^{2} \sigma_{b s 1}^{2}}{q_{1}}+\frac{f^{2} \rho_{T r 2}^{2} \sigma_{b s 2}^{2}}{q_{2}}+\cdots+\frac{f^{2} \rho_{T r m}^{2} \sigma_{b s m}^{2}}{q_{m}}+\epsilon
\end{aligned}
$$

$S_{v}^{n}=\frac{f^{n} \rho_{T r 1}^{n} \sigma_{b s 1}^{n}}{q_{1}}+\frac{f^{n} \rho_{T r 2}^{n} \sigma_{\text {bs } 2}^{n}}{q_{2}}+\cdots+\frac{f^{n} \rho_{T r m}^{n} \sigma_{b s m}^{n}}{q_{m}}+\epsilon$

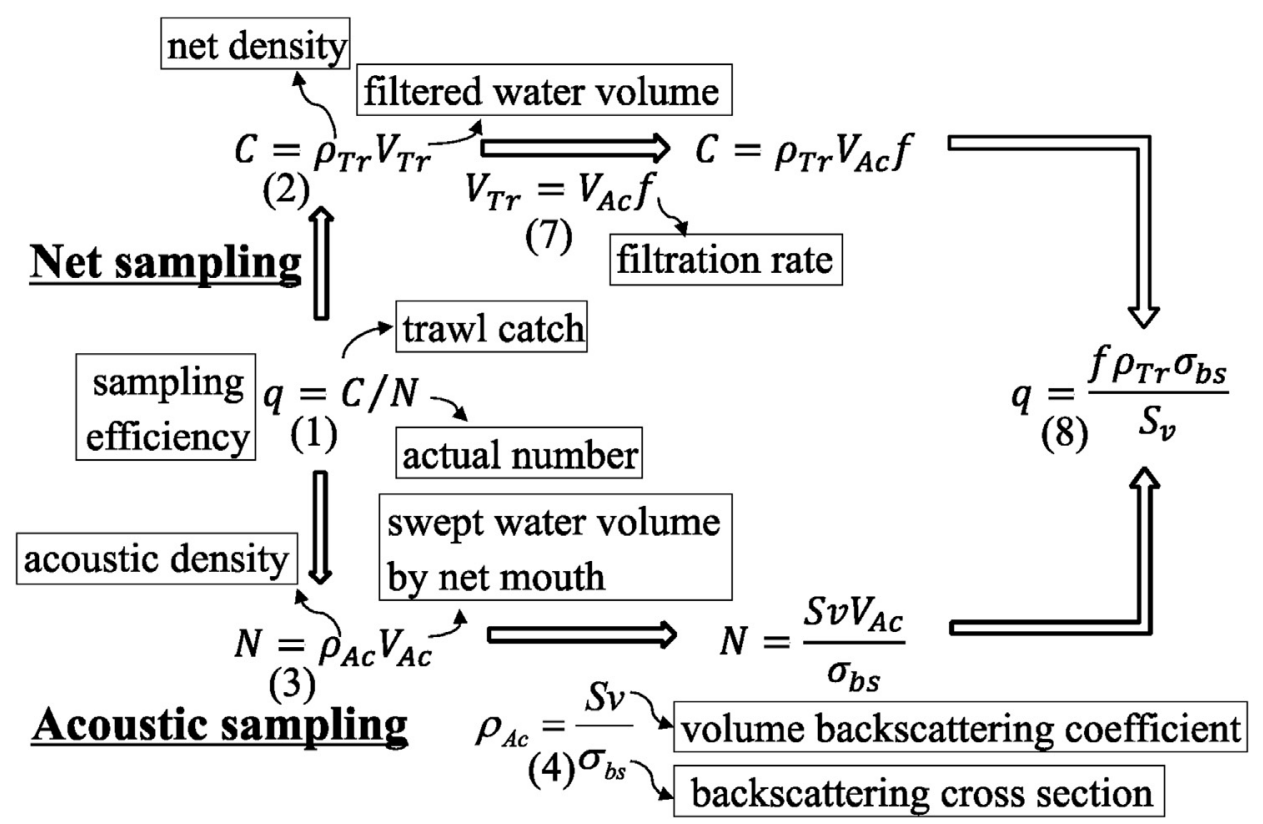

Fig. 3. A simple flow chart for the derivation of the sampling efficiency equation using acoustic data. The number below the equation corresponds to the equation number in the main article. 
where $n$ is haul number, $S_{v}^{n}$ is the mean $S_{v}$ of the towing area during the $n$th haul, $\rho_{T r m}^{n}$ is the net density of category $m$ caught during the $n$th haul, $\sigma_{b s m}^{n}$ is mean $\sigma_{b s}$ of category $m$ caught during the $n$th haul. In addition, $q_{1}$ to $q_{m}$ are the sampling efficiencies for each category of zooplankton.

The sampling efficiency was estimated by calculating the partial regression coefficient using linear regression analysis. Here, we define $S_{v}$ obtained from the quantitative echo-sounder as the response variable, and the product of $\rho_{T r}$, collected from net sampling, and $\sigma_{b s}$, calculated using an acoustic scattering model for each species, as the explanatory variables. We performed regression analysis with SPSS Statistics 23.0 (IBM) and estimated the reciprocal of the sampling efficiency $q_{m}$ by calculating the partial regression coefficient.

In order to compare the sampling efficiencies of different sampling gear for organisms with different shapes, we investigated the relationship between the equivalent spherical radius of each zooplankton category and the estimated sampling efficiency. The mean weight of an individual was obtained by dividing the total weight by the number of individuals, and the density was calculated using the density contrast described in next section as seawater density was $1030 \mathrm{~kg} \mathrm{~m}^{-3}$. The volume was then calculated using the mean weight and density for an individual to obtain the equivalent spherical radius $(\mathrm{mm})$. The sampling efficiencies of the FMT and ring net for the equivalent spherical radius were approximated by the selectivity curves of a logistic model [5].

\subsection{Target strength estimation by a theoretical model}

The TS of the target organism was estimated using a theoretical model, with the following inputs: density contrast, sound speed contrast, and shape of the target organism. The model used was the Distorted Wave Born Approximation (DWBA) model, which is typically used to estimate the acoustic scattering properties of zooplankton such as euphausiids and copepods. This model is effective when the density and the sound speed of the scatterers are close to those of seawater $[3,21,26]$. The calculation was done for a series of cylindrical slices along the body axis, whereby the scattering amplitude $f_{b s}$ and its relationship with TS were expressed using:

$$
\begin{aligned}
f_{b s}= & \int_{\vec{r}_{p o s}} \frac{k_{s w}^{2} a_{c}}{4 k_{a n}}\left(\frac{1+h^{2}}{g h^{2}}-2\right) \exp \left(2 i \vec{k}_{a n} \cdot \vec{r}_{p o s}\right) \\
& \frac{J_{1}\left(2 k_{a n} a_{c} \cos \beta_{\text {tilt }}\right)}{\cos \beta_{\text {tilt }}}\left|d \vec{r}_{p o s}\right| \\
T S= & 10 \log \left|f_{b s}\right|^{2}
\end{aligned}
$$

where, $\vec{r}_{\text {pos }}$ is the position vector on the body axis of the cylindrical slice, $k$ is the wave number $(k=2 \pi /$ $\lambda$ ), and $\lambda$ is the wavelength (m). The subscripts $s w$ and an represent seawater (surrounding medium) and animals (inside of scatter), respectively. $a_{c}$ is the radius $(\mathrm{m})$ of each thin cylinder and is obtained by digitizing the shape of the scatter, $J_{1}$ is the first-order Bessel function, and $\beta_{\text {tilt }}$ is the angle between the incident wave and the axial direction of the cylinder. $g$ and $h$ are the density contrast and sound speed contrast between the organism and the surrounding medium, respectively.

In this study, we used $g=1.053$ and $h=1.029$ for Euphausiidae based on previous findings in the waters around Hokkaido [6], and for Copepoda, $g=0.998$ and $h=1.021$ was used [20]. Since we found no prior information on the physical characteristics of Amphipoda and Chaetognatha in the waters around Hokkaido, $g=1.065$ and $h=1.005$ [7] for Amphipoda, and $g=1.003$ and $h=1.003$ [16] for Chaetognatha were used. Image processing software ImageJ [23] was used to digitize the contours and obtain $\vec{r}_{\text {pos }}$ of the target zooplankton in the side view. To calculate TS for the dorsal aspect, the $y$ and $\mathrm{z}$ axes were swapped when calculating $\vec{r}_{\text {pos }}$. The sizes of different zooplankton were obtained by enlarging or reducing the contour data of representative individuals. TS was then calculated using partially modified MATLAB (Mathworks) code by Ref. [21]. When the acoustic survey was performed using a quantitative echo-sounder, the swimming angle of zooplankton was considered to be random and, therefore, the final calculation of TS was meant across all tilt angles for the dorsal aspect (tilt-meant TS ).

\section{Results}

\subsection{Net sampling}

The number and density of each zooplankton category sampled by the FMT and ring net are shown in Table 1 and Table 2, respectively with Euphausiidae, Copepoda, Amphipoda and Chaetognatha generally being present. The dominant 
Table 1. Number $\left(C\right.$, ind.) and individual density $\left(\rho_{T r}\right.$, ind. $\left.m^{-3}\right)$ of each taxon sampled by FMT.

\begin{tabular}{|c|c|c|c|c|c|c|c|c|c|c|c|c|}
\hline \multirow[t]{2}{*}{ No. } & \multirow[t]{2}{*}{ Date } & \multicolumn{2}{|c|}{ Euphausiidae } & \multicolumn{2}{|c|}{ Copepoda } & \multicolumn{2}{|c|}{ Amphipoda } & \multicolumn{2}{|c|}{ Chaetognatha } & \multicolumn{2}{|c|}{ Others } & \multirow{2}{*}{$\begin{array}{l}\text { Towing } \\
\text { depth }\end{array}$} \\
\hline & & $\mathrm{C}$ & $\rho_{T r}$ & $\mathrm{C}$ & $\rho_{T r}$ & $\mathrm{C}$ & $\rho_{T r}$ & $\mathrm{C}$ & $\rho_{T r}$ & $\mathrm{C}$ & $\rho_{T r}$ & \\
\hline 1 & \multirow[t]{6}{*}{ 2011/Apr. } & 11040 & 1.60 & 98080 & 14.24 & 2752 & 0.40 & 7936 & 1.15 & 1888 & 0.27 & 95 \\
\hline 2 & & 11584 & 1.16 & 158464 & 15.85 & 4352 & 0.44 & 11360 & 1.14 & 3456 & 0.35 & 113 \\
\hline 3 & & 16128 & 2.52 & 138816 & 21.73 & 4192 & 0.66 & 8992 & 1.41 & 5216 & 0.82 & 49 \\
\hline 4 & & 62336 & 11.43 & 246656 & 45.24 & 6528 & 1.20 & 7424 & 1.36 & 6784 & 1.24 & 18 \\
\hline 5 & & 25152 & 5.41 & 270016 & 58.06 & 5568 & 1.20 & 12160 & 2.61 & 3776 & 0.81 & 18 \\
\hline 6 & & 43904 & 8.74 & 348800 & 69.43 & 6272 & 1.25 & 6144 & 1.22 & 4482 & 0.89 & 15 \\
\hline 7 & \multirow[t]{8}{*}{ 2011/May } & 54464 & 10.06 & 52288 & 9.65 & 3840 & 0.71 & 2688 & 0.50 & 1024 & 0.19 & 16 \\
\hline 3 & & 115968 & 22.11 & 50944 & 9.71 & 7616 & 1.45 & 2688 & 0.51 & 1152 & 0.22 & 17 \\
\hline 9 & & 30704 & 6.19 & 24320 & 4.90 & 2064 & 0.42 & 1424 & 0.29 & 1072 & 0.22 & 24 \\
\hline 10 & & 28848 & 6.26 & 39952 & 8.67 & 3152 & 0.68 & 1632 & 0.35 & 880 & 0.19 & 17 \\
\hline 11 & & 26240 & 5.21 & 59296 & 11.78 & 2432 & 0.48 & 5440 & 1.08 & 1984 & 0.39 & 176 \\
\hline 12 & & 352 & 0.09 & 129536 & 33.71 & 3552 & 0.92 & 2272 & 0.59 & 960 & 0.25 & 14 \\
\hline 13 & & 11776 & 1.41 & 29136 & 3.48 & 1632 & 0.19 & 2416 & 0.29 & 752 & 0.09 & 171 \\
\hline 14 & & 512 & 0.06 & 46176 & 5.49 & 528 & 0.06 & 304 & 0.04 & 160 & 0.02 & 9 \\
\hline 15 & \multirow[t]{6}{*}{ 2011/Jun. } & 78496 & 16.85 & 5248 & 1.13 & 7840 & 1.68 & 640 & 0.14 & 256 & 0.05 & 29 \\
\hline 16 & & 223808 & 35.46 & 4800 & 0.76 & 16443 & 2.61 & 576 & 0.09 & 960 & 0.15 & 26 \\
\hline 17 & & 67328 & 12.63 & 1792 & 0.34 & 72576 & 13.62 & 1152 & 0.22 & 16896 & 3.17 & 23 \\
\hline 13 & & 78016 & 14.50 & 2560 & 0.48 & 69696 & 12.96 & 576 & 0.11 & 128 & 0.02 & 23 \\
\hline 19 & & 992 & 0.18 & 112 & 0.02 & 9904 & 1.76 & 16 & 0.00 & 672 & 0.12 & 46 \\
\hline 20 & & 256 & 0.04 & 1232 & 0.17 & 14192 & 1.97 & 752 & 0.10 & 272 & 0.04 & 175 \\
\hline \multirow{2}{*}{\multicolumn{2}{|c|}{$\begin{array}{l}\text { Mean } \\
\text { Standard deviation }\end{array}$}} & 44395 & 8.10 & 85411 & 15.74 & 12257 & 2.23 & 3830 & 0.66 & 2639 & 0.48 & 53.70 \\
\hline & & 51688 & 8.79 & 98581 & 19.77 & 20021 & 3.74 & 3762 & 0.65 & 3746 & 0.70 & 56.84 \\
\hline
\end{tabular}

taxa in individual FMT hauls were Copepoda in April, Copepoda and Euphausiidae in May, and Euphausiidae and Amphipoda in June (Table 1). The proportions of zooplankton sampled by FMT from April to June 2011 were 29.9\%, 57.5\%, 8.3\%, $2.6 \%, 1.8 \%$ for Euphausiidae, Copepoda, Amphipoda, Chaetognatha, and other organisms, respectively (Fig. 4). In contrast, the dominant taxon in all

Table 2. Number $\left(C\right.$, ind.) and indivisual density $\left(\rho_{\text {Tr }}\right.$ ind. $\left.m^{-3}\right)$ of each taxon sampled by ring net.

\begin{tabular}{|c|c|c|c|c|c|c|c|c|c|c|c|c|}
\hline \multirow[t]{2}{*}{ No. } & \multirow[t]{2}{*}{ Date } & \multicolumn{2}{|c|}{ Euphausiidae } & \multicolumn{2}{|c|}{ Copepoda } & \multicolumn{2}{|c|}{ Amphipoda } & \multicolumn{2}{|c|}{ Chaetognatha } & \multicolumn{2}{|c|}{ Others } & \multirow{2}{*}{$\begin{array}{l}\text { Towing } \\
\text { depth }\end{array}$} \\
\hline & & $\mathrm{C}$ & $\rho_{T r}$ & $\mathrm{C}$ & $\rho_{T r}$ & $\mathrm{C}$ & $\rho_{T r}$ & $\mathrm{C}$ & $\rho_{T r}$ & $\mathrm{C}$ & $\rho_{T r}$ & \\
\hline 1 & \multirow[t]{4}{*}{ 2011/Apr. } & 69 & 2.77 & 4742 & 190.31 & 102 & 4.09 & 248 & 9.95 & 172 & 6.90 & 40 \\
\hline 2 & & 66 & 3.97 & 4619 & 278.05 & 194 & 11.68 & 178 & 10.72 & 187 & 11.26 & 40 \\
\hline 3 & & 483 & 23.65 & 3917 & 191.80 & 95 & 4.65 & 149 & 7.30 & 295 & 14.44 & 40 \\
\hline 4 & & 444 & 21.23 & 3790 & 181.24 & 101 & 4.83 & 140 & 6.69 & 210 & 10.04 & 40 \\
\hline 5 & \multirow[t]{6}{*}{ 2011/May } & 1635 & 57.52 & 4404 & 154.93 & 33 & 1.16 & 74 & 2.60 & 47 & 1.65 & 50 \\
\hline 6 & & 915 & 60.02 & 3547 & 232.67 & 21 & 1.38 & 63 & 4.13 & 36 & 2.36 & 30 \\
\hline 7 & & 1057 & 25.46 & 4626 & 111.44 & 51 & 1.23 & 84 & 2.02 & 34 & 0.82 & 50 \\
\hline 8 & & 848 & 21.27 & 4118 & 103.28 & 20 & 0.50 & 63 & 1.58 & 48 & 1.20 & 30 \\
\hline 9 & & 14 & 0.86 & 1978 & 120.83 & 1 & 0.06 & 2 & 0.12 & 7 & 0.43 & 30 \\
\hline 10 & & 263 & 2.40 & 2207 & 20.12 & 15 & 0.14 & 161 & 1.47 & 43 & 0.39 & 220 \\
\hline 11 & \multirow[t]{8}{*}{ 2011/Jun. } & 74 & 5.01 & 1252 & 84.69 & 60 & 4.06 & 14 & 0.95 & 12 & 0.81 & 30 \\
\hline 12 & & 82 & 5.37 & 1675 & 109.76 & 66 & 4.32 & 26 & 1.70 & 15 & 0.98 & 30 \\
\hline 13 & & 226 & 15.69 & 1528 & 106.09 & 65 & 4.51 & 22 & 1.53 & 6 & 0.42 & 30 \\
\hline 14 & & 263 & 16.56 & 1831 & 115.30 & 66 & 4.16 & 40 & 2.52 & 9 & 0.57 & 30 \\
\hline 15 & & 16 & 0.34 & 482 & 10.29 & 95 & 2.03 & 12 & 0.26 & 7 & 0.15 & 100 \\
\hline 16 & & 72 & 0.74 & 2605 & 26.89 & 121 & 1.25 & 283 & 2.92 & 24 & 0.25 & 220 \\
\hline 17 & & 9 & 0.20 & 561 & 12.62 & 118 & 2.65 & 13 & 0.29 & 2 & 0.04 & 100 \\
\hline 18 & & 54 & 0.63 & 936 & 11.00 & 100 & 1.17 & 97 & 1.14 & 9 & 0.11 & 200 \\
\hline \multirow{2}{*}{\multicolumn{2}{|c|}{$\begin{array}{l}\text { Mean } \\
\text { Standard deviation }\end{array}$}} & 366 & 14.65 & 2712 & 114.52 & 74 & 2.99 & 93 & 3.22 & 65 & 2.93 & 72.78 \\
\hline & & 446 & 17.89 & 1463 & 77.54 & 46 & 2.67 & 81 & 3.17 & 85 & 4.36 & 66.32 \\
\hline
\end{tabular}


(a) FMT

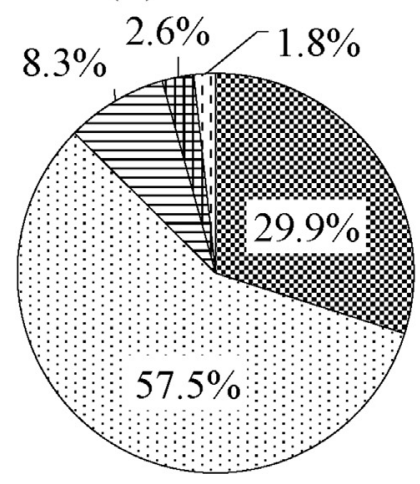

(b) $80 \mathrm{~cm}$ ring

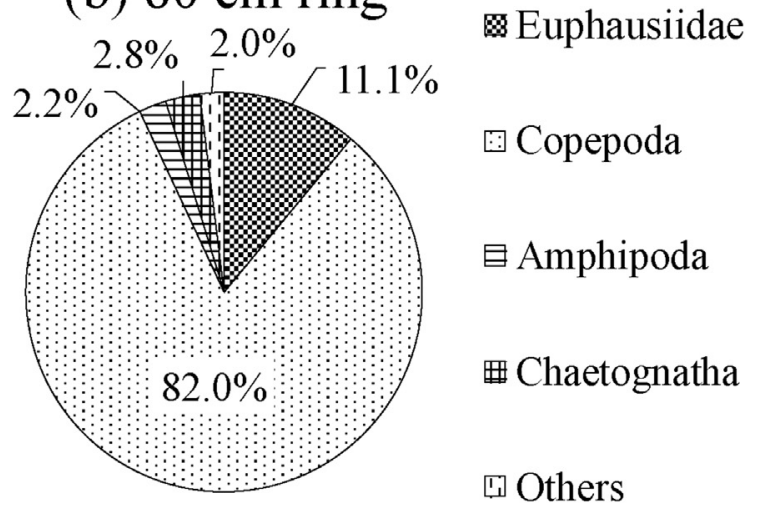

Fig. 4. Percentages of the five zooplankton taxa sampled by the (a) FMT and (b) $80 \mathrm{~cm}$ ring net.

ring net hauls was Copepoda (Table 2), and the proportions of zooplankton the above listed taxa sampled by ring net were $11.1 \%, 82.0 \%, 2.2 \%, 2.8 \%$, and $2.0 \%$, respectively (Fig. 4 ).

The wet weight composition of the zooplankton sampled by FMT, totalling $3.04 \times 10^{4} \mathrm{~g}$, was $46.2 \%$, $24.6 \%, 25.1 \%, 1.6 \%$ and $2.5 \%$ for Euphausiidae, Copepoda, Amphipoda, Chaetognatha, and other organisms, respectively (Fig. 5). The total wet weight of zooplankton sampled by ring net was $1.90 \times 10^{2} \mathrm{~g}$, with the above taxa constituting $27.7 \%, 47.7 \%$, $17.0 \%, 4.4 \%$ and $3.2 \%$, respectively. In terms of wet weight, Euphausiidae and Copepoda accounted for about half of the take of the FMT and ring net, respectively.

The body lengths of zooplankton sampled by FMT were larger than those of zooplankton sampled by the ring net (excluding Amphipoda) (Fig. 6). In addition, the length range of Euphausiidae was broad in both the FMT and the ring net samples showing a bimodal distribution. This allowed us to divide Euphausiidae into two categories, small
Euphausiidae $(0-13 \mathrm{~mm})$ and large Euphausiidae $(13-25 \mathrm{~mm})$ for calculating TS and estimating sampling efficiency (Fig. 6-A).

\subsection{Estimation of sampling efficiency for each Zooplankton category}

The mean body length of each zooplankton category was $9.75 \mathrm{~mm}, 17.06 \mathrm{~mm}, 6.32 \mathrm{~mm}, 7.54 \mathrm{~mm}$ and $19.14 \mathrm{~mm}$ for small Euphausiidae, large Euphausiidae, Copepoda, Amphipoda, Chaetognatha, respectively (Table 3 ). The calculated tilt-meant TSs of the above categories were $-101.7 \mathrm{~dB},-90.0 \mathrm{~dB}$, $-103.8 \mathrm{~dB},-101.6 \mathrm{~dB}$ and $-118.8 \mathrm{~dB}$, respectively (Table 3).

The acoustically-measured densities were significantly different (1.14-1000 times) from the gearmeasured densities for both types of gear (Tables 4 and 5). For Euphausiidae and Copepoda, the sampling efficiencies derived from the echo-sounder were found to accurately standardize the gearmeasured density. For small Euphausiidae and (a) FMT

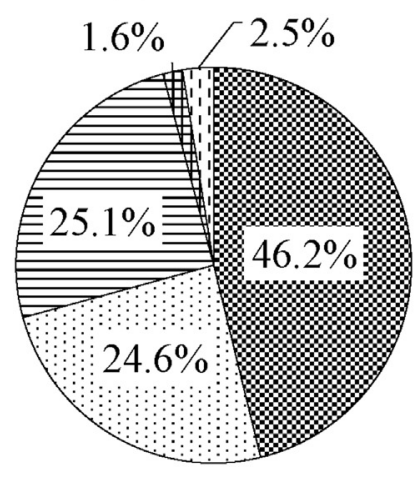

(b) $80 \mathrm{~cm}$ ring

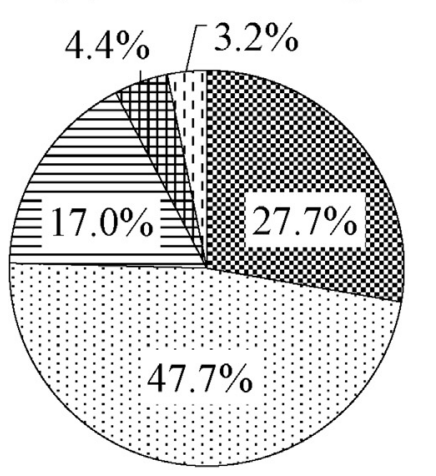

\& Euphausiidae

Copepoda

छAmphipoda

曲 Chaetognatha

田 Others

Fig. 5. Wet weight composition of the five zooplankton taxa sampled by the (a) FMT and (b) ring net. 


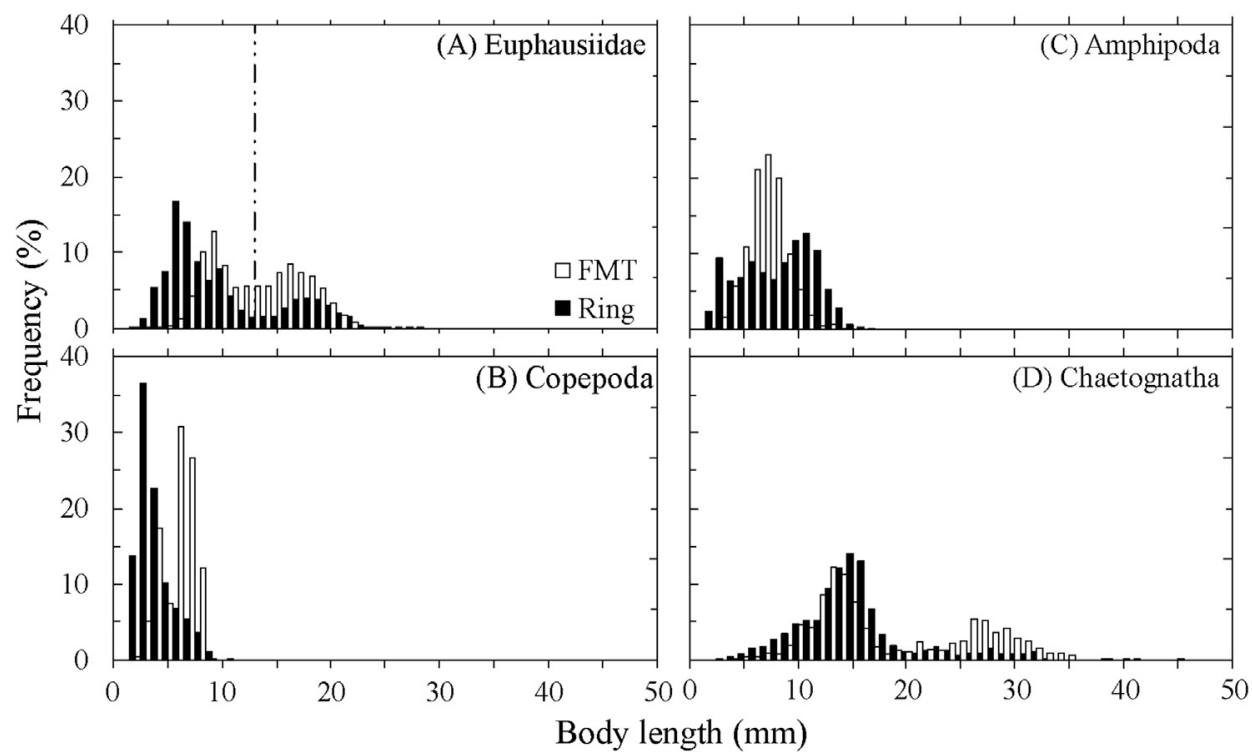

Fig. 6. Length frequency distribution of the four species of zooplankton sampled by the FMT (white) and the $80 \mathrm{~cm}$ ring net (black). Euphausiids are divided into two categories: i) greater than or equal to $13 \mathrm{~mm}$, ii) less than $13 \mathrm{~mm}$ (two-dot chain line in 6A).

Table 3. The mean body length, sound speed contrast (g), density contrast (h) and tilt-meant target strength (TTS) for each zooplankton category.

\begin{tabular}{lllll}
\hline Category & Body length $(\mathrm{mm})$ & $\mathrm{g}$ & $\mathrm{h}$ & $\begin{array}{l}\text { TTS } \\
(\mathrm{dB})\end{array}$ \\
\hline small Euphausiidae & 9.75 & 1.053 & 1.029 & -101.7 \\
large Euphausiidae & 17.06 & 1.053 & 1.029 & -90.0 \\
Copepoda & 6.32 & 0.998 & 1.021 & -103.8 \\
Amphipoda & 7.54 & 1.065 & 1.005 & -101.6 \\
Chaetognatha & 19.14 & 1.003 & 1.003 & -118.8 \\
\hline
\end{tabular}

Copepoda, the sampling efficiencies of FMT were lower than those of ring net. In contrast, for large Euphausiidae, the sampling efficiency of ring net was lower than that of FMT (Tables 4 and 5), which is likely due to large Euphausiidae being more capable swimmers, and many individuals escaped from the net mouth of small plankton nets.

The relationship between the equivalent spherical radius of each zooplankton category and the sampling efficiency of each gear showed that the

Table 4. Estimated sampling efficiency $(q)$ and significance $(p)$ values for each zooplankton category sampled by FMT.

\begin{tabular}{|c|c|c|c|c|}
\hline \multirow[t]{2}{*}{ Category } & \multirow[t]{2}{*}{ q } & \multirow[t]{2}{*}{$\mathrm{p}$} & \multicolumn{2}{|c|}{$95 \%$ Confidence interval for $\mathrm{q}$} \\
\hline & & & Lower bound & Upper bound \\
\hline $\begin{array}{l}\text { small } \\
\quad \text { Euphausiidae }\end{array}$ & 0.20 & 0.021 & 0.11 & 0.94 \\
\hline $\begin{array}{l}\text { large } \\
\text { Euphausiidae }\end{array}$ & 0.41 & $<0.001$ & 0.35 & 0.50 \\
\hline Copepoda & 0.35 & 0.029 & 0.19 & 2.54 \\
\hline Amphipoda & 0.38 & 0.170 & 0.15 & - \\
\hline Chaetognatha & 0.001 & 0.433 & $<0.001$ & - \\
\hline
\end{tabular}

Table 5. Estimated sampling efficiency $(q)$ and significance $(p)$ values for each zooplankton category sampled by ring net.

\begin{tabular}{lllll}
\hline Category & $\mathrm{q}$ & $\mathrm{p}$ & \multicolumn{2}{l}{$95 \%$ Confidence interval for $\mathrm{q}$} \\
\cline { 4 - 5 } & & & Lower bound & Upper bound \\
\hline $\begin{array}{l}\text { small } \\
\quad \text { Euphausiidae }\end{array}$ & 0.62 & 0.050 & 0.31 & - \\
$\begin{array}{l}\text { large } \\
\quad \text { Euphausiidae }\end{array}$ & 0.09 & $<0.001$ & 0.09 & 0.09 \\
$\begin{array}{l}\text { Copepoda } \\
\text { Amphipoda }\end{array}$ & 0.88 & 0.012 & 0.54 & 2.40 \\
Chaetognatha & 0.04 & 0.268 & 0.13 & - \\
\hline
\end{tabular}

sampling efficiency of the ring net decreased as the equivalent spherical radius increased, but the results from the FMT showed an opposite relationship (Fig. 7). Although the selectivity curves appear to differ from the original point data, the model results clearly revealed the sampling characteristics of different gear.

\section{Discussion}

\subsection{Estimating sampling efficiencies of plankton nets for different categories}

Since many zooplankton are mixed in the ocean and their TSs are also different, the $S v$ measured by a quantitative echo-sounder is represented by the algebraic sum of the $S v$ of each category (Eq. (9)). To estimate the acoustic biomass, the measured $S v$ must be reasonably well-explained by the sum of the $S v$ of each category. The $\sigma_{b s}$ was estimated using an acoustic scattering model for each category. The 


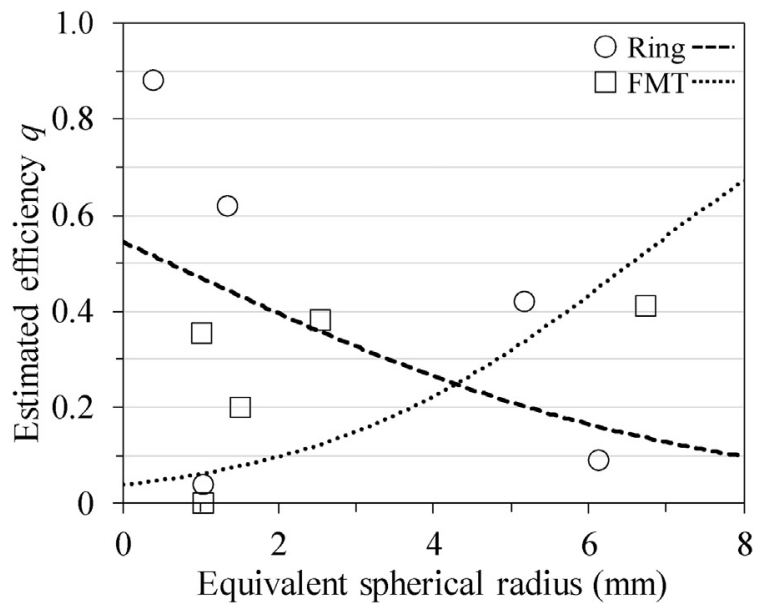

Fig. 7. The relationship between the sampling efficiencies of FMT (squares) and ring net (circles) and the equivalent spherical radius of each zooplankton category. The selectivity curves are approximated by a logistic model, and the dotted line and dashed line represent FMT and ring net, respectively.

density of sampled individuals can be obtained by categories and their lengths from the net sampling results. However, since the sampling efficiency is less than 1, the net density is generally smaller than the actual density estimated using an acoustic method. Therefore, the $S V s$ estimated by the acoustic scattering model and net density were smaller than the measured SVs (Fig. 8). It was clearly shown that there was a stronger correlation between the estimated $S V s$, using the estimated sampling efficiency and measured $S V s$, highlighting that the sampling efficiency derived from echo-sounders could be used to accurately standardize plankton net sampling data. However, the differences between the measured $S V s$ and the estimated $S V s$ were not consistent. Possible causes include the validity of the acoustic scattering model, the uncertainty of the length distribution and swimming angle distribution, and the presence of additional scattering material (e.g., jellyfish).

The densities for different zooplankton categories were estimated using an acoustic method and were compared with the net densities to estimate the sampling efficiencies of two types of gear: the FMT and ring net. Echo-sounder-derived sampling efficiency accurately standardized gear density for Euphausiidae and Copepoda, but not for Amphipoda and Chaetognatha (Tables 4 and 5). This may be due to the proportion of the sampled Euphausiidae and Copepoda, and their contribution rate to $S v$, were higher than Amphipoda and Chaetognatha. It was found that the Pearson correlation coefficient between the estimated $S v$ of large Euphausiidae and the measured $S v$ was higher than

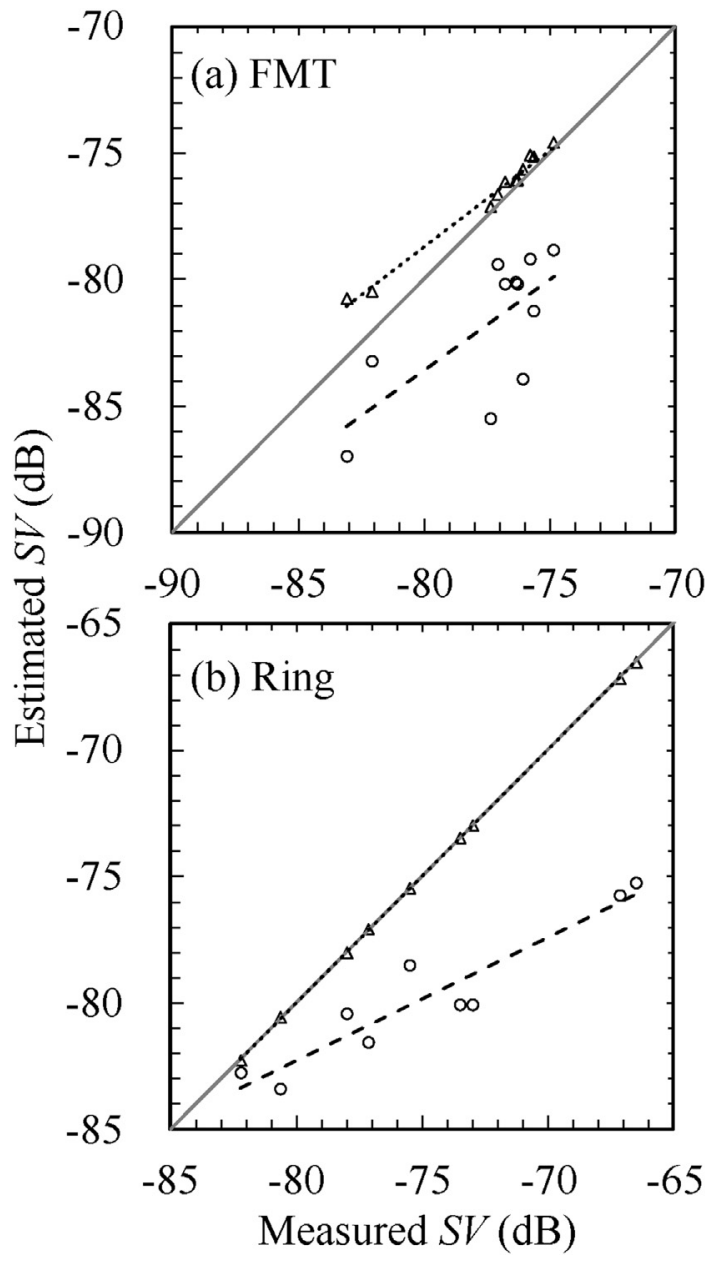

Fig. 8. Relationship between the estimated SV and the measured SV for (a) FMT and(b) ring net. Estimated SVs were calculated in two cases: i) the sampling efficiency was assumed to be 1 and SVs were calculated using Eq. (9) (circles), ii) the sampling efficiency was obtained from the actual measures and SVs were calculated using Eq. (10) (triangles).

that of other categories, which means that the contribution rate of large Euphausiidae was high (Table 6). Based on FMT tows, both large and small Euphausiidae had a higher contribution rate to $S v$ than other categories. Therefore, the sampling efficiency for Euphausiidae was estimated significantly (Table 4). For the ring net, large Euphausiidae and Copepoda had a higher contribution rate to $S v$ than other categories. Therefore, it was considered that the sampling efficiency for both large Euphausiidae and Copepoda could be estimated with a high significance level (Table 5). The sampling efficiency for Amphipoda and Chaetognatha was inconclusive $(p>0.1)$, which is likely due to the few net samples containing large numbers of Amphipoda and Chaetognatha. To estimate sampling efficiency for these taxa, haul effort should be increased in survey areas where amphipods and chaetognaths are more abundant. 
Table 6. Pearson correlation between measured Sv and estimated Sv of each zooplankton category for both types of gear.

\begin{tabular}{lll}
\hline Category & \multicolumn{2}{l}{ Measured Sv as towing } \\
\cline { 2 - 3 } & FMT & $80 \mathrm{~cm}$ ring net \\
\hline small Euphausiidae & 0.46 & -0.35 \\
large Euphausiidae & 0.95 & 0.99 \\
Copepoda & 0.16 & 0.32 \\
Amphipoda & 0.17 & 0.02 \\
Chaetognatha & 0.07 & 0.31 \\
\hline
\end{tabular}

The sampling efficiencies of the FMT and ring net were derived for five zooplankton categories using a single-frequency echo-sounder. It was important to select the corresponding and appropriate frequency for various sizes and categories. Madureria et al. [18] showed that the 120 and $200 \mathrm{kHz}$ were effective for quantifying the abundance of three species of Antarctic macroplankton containing two types of Euphausiidae and Amphipoda. Kim et al. [13] showed that the $S V$ differences between 120 and 200 $\mathrm{kHz}\left(\Delta S V_{200-120 \mathrm{kHz}}\right)$ were $2.4 \pm 2.5 \mathrm{~dB}$ for copepods $2.5 \pm 1.1 \mathrm{~mm}$ in length. As shown by the results, the sampling efficiency for Copepoda, which had the smallest length in five categories, was estimated with a high degree of certainty (Tables 4 and 5). Taking into account the detection range and the noise level of the high frequency, we found that the single frequency of $120 \mathrm{kHz}$ was adequate for our study. Although the sampling efficiency characterizes the sampling gear and does not change with the selected frequency, it is necessary to estimate the sampling efficiencies of different gear using a range of frequencies to select the most appropriate frequency for the target species. Future work will aim to increase samples of dominant category and use an appropriate frequency, which will provide more accurate estimates of the sampling efficiency of each gear.

\subsection{Quantitative sampling of Zooplankton}

The sampling efficiencies of the ring net were higher than those of FMT for small Euphausiidae and Copepoda, (Tables 4 and 5). In contrast, the ring net was less effective than FMT for large Euphausiidae (Tables 4 and 5). For the relationship between the equivalent spherical radius of each zooplankton category and the sampling efficiency, we found that the sampling efficiency of the ring net decreased as the equivalent spherical radius increased, but the results of FMT showed the opposite relationship (Fig. 7). This was deemed to be the cause of the ring net having a smaller mesh and poor-swimming organisms entering the net were generally retained, while organisms that were stronger swimmers evaded the small net mouth area. For the FMT, it is believed that the large mouth area and relatively high towing speed made it difficult for zooplankton to avoid the gear, but the smaller organisms entering the net were more likely to escape from the coarse mesh. Thus, when sampling zooplankton, the entering rate of ring net and the retention rate of FMT are the main factors affecting the sampling efficiencies of these gear. We also found that even though the equivalent spherical radiuses were similar, the sampling efficiencies of same gear were entirely different, which is likely due to different forms of zooplankton. In future research, we will expand the number of samples and categories to obtain a more accurate model curve.

Since the FMT has a large net mouth area and a faster towing speed, the sampling efficiency for zooplankton was mainly affected by the retention rate (mesh selectivity) related to the mesh opening. Fujimori et al. [5] performed size selectivity estimation for euphausiids using expanded SELECT analysis for a subsample from the trousers trawl experiment. Using Eq. (8), we estimated the sampling efficiency for the FMT samples dominated by Euphausiidae, which accounted for over $80 \%$ of zooplankton composition (Fig. 9), then compared the results with the size selectivity from Fujimori et al. [5]. For euphausiids of the same size range, the estimated sampling efficiency was lower than the selectivity estimated by Fujimori et al. [5]. Regarding this cause, Fujimori et al. [5] estiamted the selectivity for FMT with two cod-ends that had different mesh openings $1.7 \mathrm{~mm}$ and $0.526 \mathrm{~mm}$, and the selectivity of a cod-end with mesh opening $0.526 \mathrm{~mm}$ was

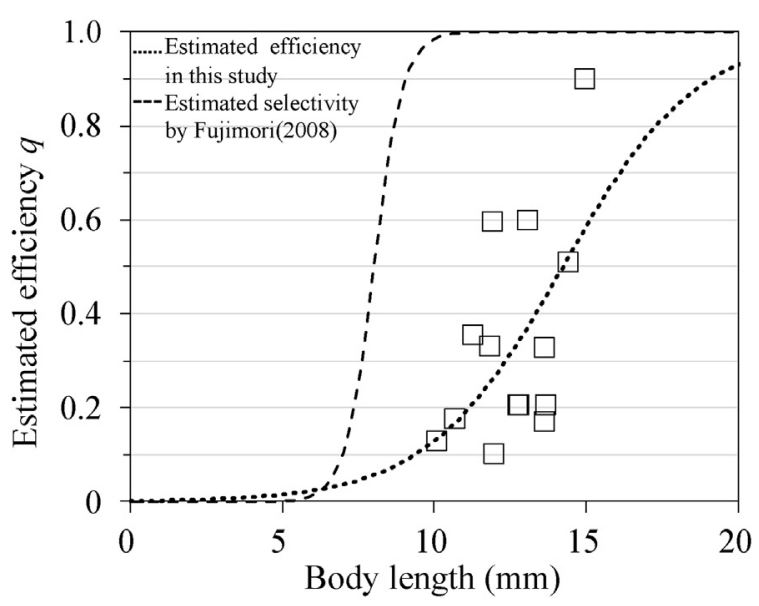

Fig. 9. Comparison between the estimated sampling efficiencies (squares) of the FMT and the mesh selectivity (dashed line) estimated by Ref. [5] for euphausia. The sampling efficiencies were estimated using Eq. (8) and fitted with a logistic model (dotted line). 
calculated as 1 . The sampling efficiency estimated in this study includes not only mesh selectivity (retention rate), but also net mouth selectivity (entering rate).

The gear sampling method is required to estimate the abundance of fisheries resources and to investigate the feeding environment of larvae and juveniles. Various sampling devices have been devised, such as the ring net, NORPAC, and IKMT, and there are also various hauling methods, such as horizontal tows, oblique tows, and vertical hauls. However, the sampling characteristics of these different plankton nets vary considerably, and it is not possible to obtain quantitative density measurements directly from the net sampling data. Even in the case of only one taxon, the larvae and adults often differ in length, swimming ability, and habitat, so it is almost impossible to quantify various plankton communities distributed over a wide area using a singular type of sampling gear.

Although not covered in this study, NORPAC is widely used as an international standard net for zooplankton collection. It was decided to use a ring with diameter $45 \mathrm{~cm}$ and mesh opening $0.335 \mathrm{~mm}$ (NMG52) to perform vertical hauls from $100 \mathrm{~m}$ to surface layer at $1 \mathrm{~m} \mathrm{~s}^{-1}$, making it easy to compare data with other areas. The ring net used in this study has a mouth diameter of $80 \mathrm{~cm}$ and mesh opening of $0.5 \mathrm{~mm}$, which is vertically hauled at a speed of 1 $\mathrm{m} \mathrm{s}^{-1}$. Therefore, the sampling efficiency for medium-sized zooplankton would likely be higher using the $80 \mathrm{~cm}$ ring net than using NORPAC net, but lower for microzooplankton smaller than 0.5 $\mathrm{mm}$. Due to its large mouth diameter, vertical hauls from deeper layers is physically challenging and therefore sampling is generally limited to middepth.

To collect organisms with swimming ability such as juveniles and large euphausiids, MatsudaOozeki-Hu Trawl MOHT [8], is an alternative type of survey gear that has a large mouth area of $5 \mathrm{~m}^{2}$, a large mesh opening of $1.95 \mathrm{~mm}$, and can be towed at a high speed of 4 knots. Based on the findings from our experiments, the sampling efficiency of the MOHT would likely be higher than FMT when trawling for large euphausiids, but lower when trawling for small organisms. Due to the large size of MOHT sampling gear, trawls are restricted to large survey vessels. Therefore, the sampling efficiency and gear use restrictions impose considerable limits on quantifying the total density of zooplankton from the sampling gear.

Finally, it is important to determine the when (season and time zone), where (sea area and depth), type (range of species) and quantity (biomass and abundance) when carrying out zooplankton surveys. In order to obtain accurate measurements of zooplankton by sampling gear, it is imperative to standardize the data using the sampling efficiency of each sampling gear. Our results can also be applied to other fishing sampling gear, allowing the results of past and future zooplankton surveys to be compared more easily.

\section{Acknowledgments}

We would like to thank the captain and crew of T/ $S$ Ushiomaru for their kind assistance during the surveys. We gratefully acknowledge Assistant Professor K. Hasegawa of Hokkaido University for providing valuable suggestions. Special thanks to the laboratory members 'SOKKIES' for their valuable technical assistance. We also thank Dr. D. M. Spencer for his valuable comments and English editing. This paper was improved following comments from anonymous reviewers and editors.

\section{References}

[1] Barkley RA. Selectivity of towed-net samplers. Fish Bull 1972; 70:799-820.

[2] Brodeur RD, Daly EA, Benkwitt CE, Morgan CA, Emmett RL. Catching the prey: sampling juvenile fish and invertebrate prey fields of juvenile Coho and Chinook salmon during their early marine residence. Fish Res 2011;108:65-73.

[3] Chu D, Foote KG, Stanton TK. Further analysis of target strength measurements of Antarctic krill at 38 and $120 \mathrm{kHz}$ : Comparison with deformed cylinder model and inference of orientation distribution. J Acoust Soc Am 1993;93:2985-8.

[4] Foote KG, Knudsen HP, Vestnes G, MacLennan DN, Simmonds EJ. Calibration of acoustic instruments for fish density estimation: a practical guide. Technical Report. ICES Coop Res Rep 1987;144.

[5] Fujimori Y, Yamashita Y, Abe M, Itaya K, Mukai T. A trousers-type framed midwater trawl for simultaneous sampling of plankton and micronekton. Fish Eng 2008;44: 197-204 [in Japanese, with English Abstract].

[6] Fukuda Y, Mukai T, Sawada K, Iida K. Lateral target strength of Euphausia pacifica measured by a tethered method. Nippon Suisan Gakkaishi 2012;78:388-98 [in Japanese, with English abstract].

[7] Greenlaw CF. Backscattering spectra of preserved zooplankton. J Acoust Soc Am 1977;62:44-52.

[8] Hu F, Oozeki Y, Matsuda T. Scale model of a new midwater trawl system for sampling pelagic larval and juvenile fish. Fish Sci 2001;67:254-9.

[9] Iida K. Biomass estimation of marine zooplankton using hydroacoustics. J Marine Acoust Soc Jpn 1995;22:17-25 [in Japanese].

[10] Iida K, Mukai T, Hwang D. Relationship between acoustic backscattering strength and density of zooplankton in the sound-scattering layer. ICES (Int Counc Explor Sea) J Mar Sci 1996;53:507-12.

[11] Itaya K, Fujimori Y, Shiode D, Aoki I, Yonezawa T, Shimizu $S$, et al. Sampling performance and operational quality of a frame trawl used to catch juvenile fishes. Fish Sci 2001;67:436-43.

[12] Itaya K, Fujimori Y, Shimizu S, Komatsu T, Miura T. Effect of towing speed and net mouth size on catch efficiency in framed midwater trawls. Fish Sci 2007;73:1007-16. 
[13] Kim U, Mukai T, Iida K. Acoustic identification of krill and copepods using frequency differences of volume backscattering strength around Funka Bay, Hokkaido, Japan. Nippon Suisan Gakkaishi 2016;82:587-600 [in Japanese, with English abstract].

[14] Kirsch J, Thomas GL, Cooney RT. Acoustic estimates of zooplankton distribution in Prince William Sound, spring 1996. Fish Res 2000;47:245-60.

[15] Kobari T, Ikeda T. Life cycle of Neocalanus species in the Oyashio region. Bull Plankton Soc Jpn 2000;47:129-35 [in Japanese, with English abstract].

[16] Lawson GL, Wiebe PH, Ashjian CJ, Gallager SM, Davis CS, Warren JD. Acoustically inferred zooplankton distribution in relation to hydrography west of the Antartic Peninsula. Deep-Sea Res ? 2004;51:2041-71.

[17] Lu Z, Mukai T, Fujimori Y, Iida K. Estimating the catch efficiency of a framed midwater trawl for juvenile walleye pollock (Gadus chalcogrammus) using an acoustic method. Fish Eng 2018;55:135-44 [in Japanese, with English abstract].

[18] Madureira LSP, Ward P, Atkinson A. Differences in backscattering strength determined at 120 and $38 \mathrm{kHz}$ for three species of Antarctic macroplankton. Mar Ecol Prog Ser 1993; 93:17-24.

[19] Mair AM, Fernandes PG, Dhaussy AL, Brierley AS. An investigation into the zooplankton composition of prominent $38-\mathrm{kHz}$ scattering layer in the North Sea. J Plankton Res 2005; 27:623-33.
[20] Matsukura R, Yasuma $H$, Murase $H$, Yonezaki $S$, Funamoto $\mathrm{T}$, Honda $\mathrm{S}$, et al. Measurement of density contrast and sound-speed contrast for target strength estimation of Neocalanus copepods (Neocalanus cristatus and Neocalanus plumchrus) in the North Pacific Ocean. Fish Sci 2009;75:1377-87 [in Japanese, with English abstract].

[21] McGehee DE, O'Driscoll RL, Martin Traykovski LV. Effects of orientation on acoustic scattering from Antarctic krill at 120 kHz. Deep-Sea Res II 1998;45:1273-94.

[22] Motoda S. Devices of simple plankton apparatus. Mem Facul Fish Sci 1959;7:73-94. Hokkaido University.

[23] Schneider CA, Rasband WS, Eliceiri KW. NIH Image to ImageJ: 25 years of image analysis. Nat Methods 2012;9: 671-5.

[24] Smith PE, Counts RC, Clutter RI. Changes in filtering efficiency of plankton nets due to clogging under tow. ICES (Int Counc Explor Sea) J Mar Sci 1968;32:232-48.

[25] Somerton D, Ianelli J, Walsh S, Smith S, Godø O, Ramm D. Incorporating experimentally derived estimates of survey trawl efficiency into the stock assessment process: a discussion. ICES (Int Counc Explor Sea) J Mar Sci 1999;56:299-302.

[26] Stanton TK, Chu D. Review and recommendations for the modelling of acoustic scattering by fluid-like elongated zooplankton: euphausiids and copepods. ICES (Int Counc Explor Sea) J Mar Sci 2000;57:793-807.

[27] Stehle M, Santos A, Queiroga H. Comparison of zooplankton sampling performance of Longhurst-Hardy plankton recorder and bongo nets. J Plankton Res 2007;29:169-77. 